\title{
The relationship between social capital and knowledge management in knowledge-based organizations
}

\author{
Tahereh Aghamirzaee $^{\mathrm{a}^{*}}$, Mojtaba Tabari ${ }^{\mathrm{b}}$ and Faranak Paydar ${ }^{\mathrm{c}}$
}

\begin{abstract}
${ }^{a}$ Msc, Dept. of Management, Faculty of Management, Mazandaran University Science \& Technology, Babol, Iran
${ }^{b}$ Assist. Prof. \& Faculty Member, Dept. of Management, Faculty of Humanities, Ghaemshahr Branch, Islamic Azad University(ISU), Ghaemshahr, Iran

${ }^{c}$ Phd. Student, Dept. of Education, Faculty of Humanities, Sari Branch Islamic Azad University(ISU), Sari, Iran

CHR ON I C LE AB S T RACT

Article history:

Received June 12, 2014

Accepted 26 November 2014

Available online

November 272014

Knowledge management

Social capital

Faculty member

Knowledge based organizations

This paper presents a survey on relationship between social capital and knowledge management for knowledge based organizations. This research is of descriptive-correlation one and the sample includes 100 faculty members of non-governmental institutes of Babol city. The instrument was questionnaire and the analysis performed using SPSS17 and Lisrel 8.8 software. Pearson correlation test, multiple regression analysis route analysis, and structural equations modeling were used as statistical tests. The research showed that social capital had direct and significant effect on knowledge management in $99 \%$ confidence interval. Among the dimensions of social capital, trust and social norms with knowledge application; trust with knowledge acquisition; trust and social norms with knowledge transfer; trust and networks association with knowledge creation; and trust, social norms and networks association with knowledge record had significant and positive effects in $95 \%$ confidence interval. Social capital was effective on knowledge management and knowledge based organizations could promote knowledge creation, acquisition, record, application and transfer process by improving social capitals.
\end{abstract}

\section{Introduction}

Nowadays, the primary objective of knowledge management is to increase individuals' motivation for knowledge management to achieve the strategic, scientific and applicable goals and obtaining the only source of sustainable competitive advantage, which is knowledge. If an organization is able to increase effective interactions among its staffs, groups and organizational units, there will be new knowledge creation within the organization, transfer, and exchange among individuals and the effect of organizational knowledge management will be increased. Successful managers have always recognized and use their intellectual properties within the organization. However, these activities are often done unsystematically and unstructured, thus nowadays, more attentions are paid to the role of social capital in the process of learning and knowledge management and managers pay attention to this capital as the main axis of management in organizations in order to achieve the goals, easier. 
Knowledge is created within the individuals thought and the action of the member of the organization and mainly appears by the social process of the organization, the social capital by the social process of the organization, and social capital is considered as the source for facilitating the relationship among individuals. This source includes institutions, norms, trust, participation, awareness and many other cases, which prevails over relationships and interactions among individuals and can have different outcomes and results on individuals' performance within the organizations.

Educational organizations, in terms of breadth and diversity of intellectual capital, are the most widespread formal social institutions and should be leader and pioneer in this field. Highly educated people have different missions in evolutionary path and these missions have been actually a kind of response to the environment. The newly found duty of high education system is to change, transform and improve the social and human capital to intelligence capital. This creates conductive environments by creating and developing culture and values in organizations to all individuals. In fact, knowledge belongs to the whole organization and participates in innovations and the movement of the organization accelerates toward knowledge creation, sharing, acquisition and application. The above literature shows that organizations can be successful in developing organizational knowledge by creating the atmosphere of trust, cooperation and participation among the member of the organization.

Robert Putnam defines social capital as "a set of trust, norms and network link which facilitate the cooperation for mutual benefit which results are different kinds of collective action. He considers three components for social capital: awareness, participation and civil institutions" (Winter, 2000:3). Coleman (1998) for defining social capital got help from its role and functions and presented a functional definition for social capital. From his view, the social capital is not a single object but it has two common features: first, all of them are an aspect of social structures. Second, facilitate the certain actions of people within the structure. He considers these indexes for social capital: 1) created commitments 2) information access 3 ) social norms 4) authority 5) identity. From the Coleman's view social capital is the combination of social structures which facilitate the certain actions of activist within these structures that finally brings human capital for individuals.

According to Pear Bourdieu (Chalabi, 1996), social capital is the sum of actual and potential resources, which are the result of ownership of durable networks of institutionalized relations among individuals, in simpler terms, membership in group for gaining the resources of that group. Indeed, network links should be of a certain type, it means, it should be positive and based on trust. According to Bourdieu, social capital may finally entail economic capital and has two major indexes: 1) trust 2) link.

From the view of Francis Fukuyama, social capital is the existence of a certain set of informal norms or values that the members of group are allowed among them are participated. Participation in values and norms does not produce social capital itself, because these values and norms may lead to norms and values. Fukuyama highlights two points in relation to social capital: 1) social capital belongs to groups not to an individual. 2) Cooperation and collaboration are necessary for the all social activities (whether bad or good). Therefore, informal values and norms can be positive or negative (Alagheh band 2005). According to the definition of components of social capital, four dimensions are common: 1) participation in networks 2) interrelationships 3) social norms and values 4) trust.

Knowledge management and its related area emphasizes the fact that in the new global economy, obtaining the sustainable competitive advantage depends on the capacity and ability of organization in development and proper use of knowledge-based resources of the organization. Knowledge management is the systematic and apparent management of knowledge, which links to the process of knowledge creation, collection, organization, distribution and application. In knowledge management, converting the individual knowledge into collective knowledge is important to be used 
widely throughout the organization. In knowledge application two points are important: knowledge sharing and innovation (Skyrme, 1997).

Bhatt also defines the knowledge management cycle as the activities of knowledge acquisition, record, transfer, creation and application in an organization. Knowledge acquisition includes a set of activities executed in order to acquire new knowledge from the outside of the organization. Activities such as the rate of participation of the members in scientific associations and participation rate in training courses. The cooperation of the organization with universities and other scientific centers, buying the new knowledge for organization is the indicator of the amount of effort for acquiring the new knowledge and its entrance to the organization. Knowledge record and documentation includes a set of activities, which are applied in order to record the existing knowledge in the organization. Activities like using the databases for recording the organizational knowledge, documentation of successful and unsuccessful experiences are one of the activities of knowledge record in the organization.

Knowledge transfer includes a set of activities, which are executed in order to transfer knowledge of the organization among the members. Activities such as discussion and exchanging experiences and work practices meetings, members' inclination and participation for cooperation and assistance to coworkers to improve the way of working, using the databases and share knowledge of the organization to all the members are the indicator of organization's amount of effort for transferring the organizational knowledge. Knowledge creation includes a set of activities by which new knowledge produce in the organization.

Activities like reward and encouragement to innovations and new ideas of staffs, clear discussion about experiences and failures of the organization, formation of the learning groups in the organization are all such activities that facilitate the creation of new knowledge in the organization. In addition, knowledge application includes activities, which indicate that the organizational process is one of the activities of knowledge application in the organization (Alvani, 2007).

As mentioned, transferring the information and knowledge in macro and micro level between individuals and organizations depends on people who facilitate and accelerate this transfer. Modern organizations should establish their bases of sustainable competitive advantage on intangible properties and intellectual capitals. Competitive advantage further originates from the knowledge of manpower and social capital has more important role rather than physical and financial capital. If an organization is able to increase the more effective interactions among its employees, within the groups and organizational units, the more can ensure toward the effectiveness of the information exchange among its staff and thus, effective management of organizational knowledge (Bhatt, 2001).

Therefore, establishment and development of the culture and atmosphere in the organization, which encourage this kind of communications and interactions are the necessities for the knowledge management. Many researchers have decided to test and explain the relationship among social capital and dimensions, processes and several activities of knowledge management in the organization. Empirical studies which study and investigate the relationship between social capital and different activities of knowledge management do not have much span. Such noticeable studies of the researchers in this domain searched the relationship between social capital and knowledge management would be as the following:

Adler and Krwon (2002) showed that there was a meaningful relationship between social capital and knowledge transfer in the organization. Landry et al. (2002) achieved the evidences based on the relationship between social capital and knowledge management. However, they considered knowledge management generally and without separating its different dimensions in his research. Tymon and Stumpf (2003) showed the relationship between social capital and knowledge management (again in general concept) obtaining higher function by the organization. Das and Teng 
(2002) showed that the existence of social capital in the organization would be effective on knowledge transfer among members of the networks. Mahmodi Topkanlo (2011) showed that there was a positive correlation between the amount of social capital and three cognitive, relational and structural dimensions and the amount of implementation of the knowledge management and among the dimensions of social capital, relational dimension had high correlation with the amount of implementation of knowledge management. Demori (2009) showed that there was a positive and meaningful relationship between social capital and knowledge management. Therefore, social capital played important role in developing the knowledge management in Islamic universities. Alvani et al. (2007) showed that the existence of social capital was effective on developing soft activities of knowledge management. Zomorodiyan (2010) showed that there was a meaningful relationship between social capital and the variables of the preparation of knowledge management. Golmohmadnejad and Mahdavi (2011) showed that there was a meaningful and direct relationship between social capital and indexes of knowledge management. Aebeli and Zareh Khalili (2013) showed that there was a positive and meaningful relationship between social capital and knowledge management and moreover the results of the correlation test showed that all the indexes of social capital had the positive and meaningful relationship with knowledge management.

The results of surveys in mentioned researches showed that the concept of social capital and knowledge management had been used generally and several dimensions of social capital and knowledge management had not been investigated. Meanwhile, more researches have been studied just one dimension of variables. In addition, statistical population of the more researches is the manufacturing companies while universities and educational centers have the special importance in this domain. So according to what is said, this article tries to investigate the relationship between social capital (including participation in networks, interrelation ships, social norms and values, trust) and processes of knowledge management (including knowledge acquisition, transfer, creation and application) in universities and high education centers (Fig 1).

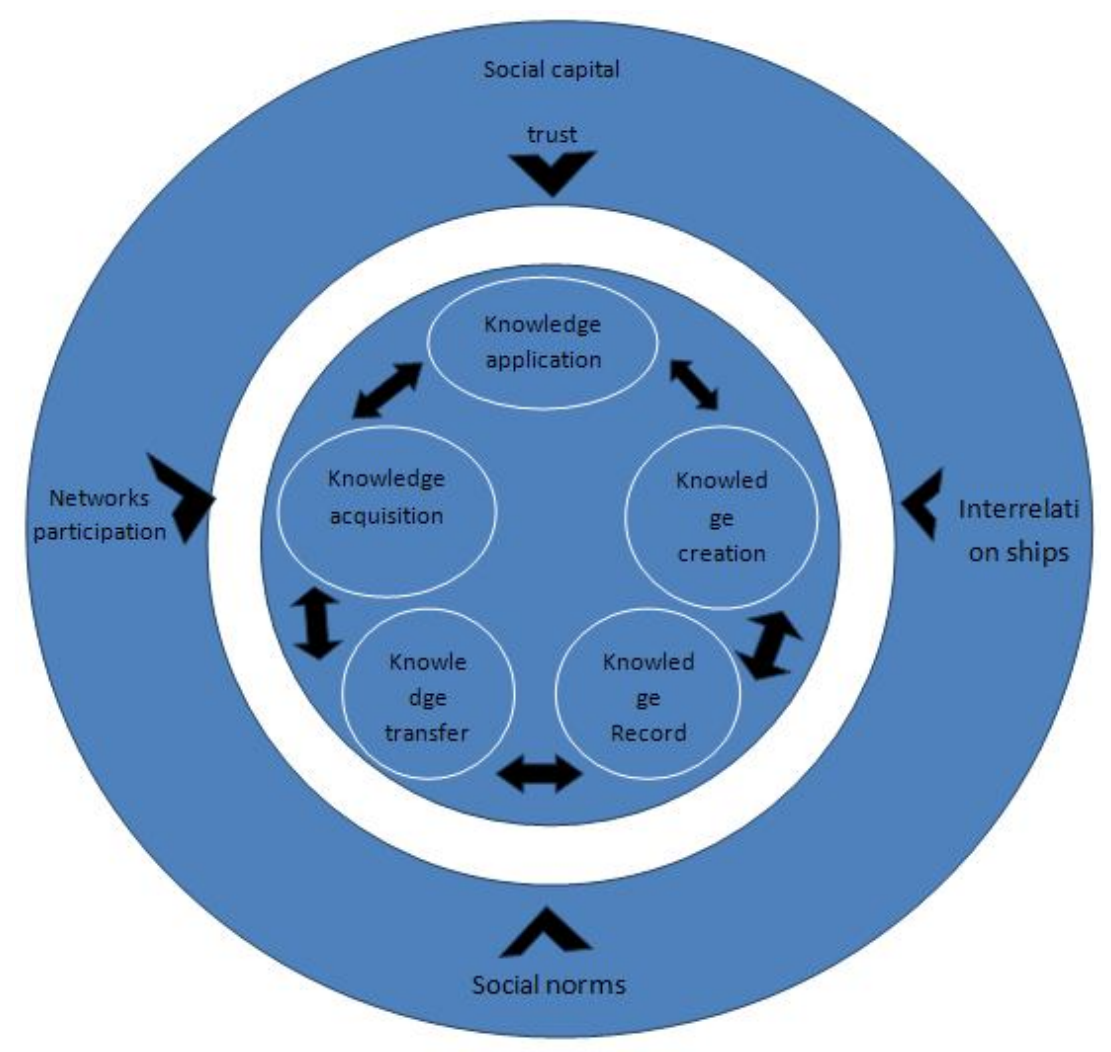

Fig. 1. Research Model 


\section{Methodology and Measures}

The method of data collection is library-field. According to the goals of this research and its nature, two standard questionnaires including 60 questions for investigating social capital (Moghimi, 2008) and 46 questions for investigating knowledge management are used (de Jong \& Roelofs, 2000). Cronbach alpha method was used by the help of spss 17 software. Therefore, the estimated Cronbach coefficient alpha for the social capital questionnaire is 0.877 and for knowledge management questionnaire is 0.944 . The statistical population of this research are formed all the faculty members of non-governmental universities of Babol, located in north part of Iran. The statistical sample is 100 faculty members. The results of analysis of the study is performed by descriptive and inferential statistics using LISRL 8.8 and spss 17 software. After collecting the raw data and extracting them in order to analyze these data, the inferential statistics (correlation coefficient and regression and route analysis, structural equations model) was used to survey the relationship among research's variables (knowledge management, social capital and its dimensions). The results of hypothesis testing presented and analyzed by the help of Pearson correlation for measuring the meaningfulness of the relationship and method of structural equation modeling and for measuring the relationship of the examined variables in two groups of main and sub- hypotheses.

Research hypothesis are proposed as following:

Main hypothesis: There is a meaningful relationship between social capital and knowledge management.

Sub-hypotheses 1: There is a meaningful relationship between social capital and knowledge application.

Sub-hypotheses 2: There is a meaningful relationship between social capital and knowledge acquisition.

Sub-hypotheses 3: There is a meaningful relationship between social capital and knowledge transfer.

Sub-hypotheses 4: There is a meaningful relationship between social capital and knowledge creation.

Sub-hypotheses 5: There is a meaningful relationship between social capital and knowledge record.

\section{Results}

Findings of the research shows that the average dimensions of social capital in the studied centers would be at intermediate level, but the average dimensions of knowledge management would be the lower level of the intermediate (Table 1).

\section{Table 1}

The average of indexes of social capital and knowledge management

\begin{tabular}{ll}
\hline Index & Average \\
\hline Trust & $3.3 \pm 0.41$ \\
Networks participation & $3.2 \pm 0.64$ \\
Interrelation ships & $3.1 \pm 0.45$ \\
Social norms and values & $3.3 \pm 0.7$ \\
Knowledge creation & $2.03 \pm 0.47$ \\
Knowledge acquisition & $2.5 \pm 0.45$ \\
Knowledge application & $1.7 \pm 0.4$ \\
Knowledge record & $2.2 \pm 0.43$ \\
Knowledge transfer & $2.03 \pm 0.36$ \\
\hline
\end{tabular}

Also the findings of the research shows that there is a positive and meaningful relationship between social capital and knowledge management $(\mathrm{p}=0.011 ; \mathrm{r}=0.321)$ (Table 2$)$. 
Table 2

Pearson correlation coefficient of the main hypothesis

\begin{tabular}{lcc}
\hline & Knowledge management & sig \\
\hline Social capital & 0.321 & 0.011 \\
\hline
\end{tabular}

In the result of the test, coefficients model like route coefficient, meaningfulness coefficient, index model $\mathrm{R}^{2}$ and circumstantial evidence $t$, which is larger than 1.96 have confirmed this point that social capital in the studied population had a direct and meaningful effect on knowledge management in $95 \%$ confidence level (Table 3 ).

Table 3

Index model

\begin{tabular}{cccccc}
\hline route & route coefficient & sig & $\mathrm{t}$ & $\mathrm{F}$ & $\mathrm{R}^{2}$ \\
\hline knowledge management... social capital & 0.321 & 0.023 & 3.460 & 5.531 & 0.103 \\
\hline
\end{tabular}

And the following regression formula can be written:

Knowledge management $=0.321$ ( social capital $)+1.723$

Investigating the sub-hypothesis shows that among the dimensions of social capital only two dimensions of trust ( $\mathrm{sig}=0.013 ; \mathrm{r}=0.314)$ and social norms $(\mathrm{sig}=0.015 ; \mathrm{r}=0.308)$ had a positive and meaningful relationship with knowledge application in $95 \%$ confidence level and two other dimensions interrelationships and networks participation did not have meaningful relationship with knowledge application. The trust dimension ( $\mathrm{sig}=0.004 ; \mathrm{r}=0.376$ ) had a positive and meaningful relationship with knowledge acquisition in 99\% confidence level, and three other dimensions interrelationships and networks participation and social norms did not have meaningful relationship with knowledge acquisition. Two dimensions of trust ( $\mathrm{sig}=0.013 ; \mathrm{r}=0.316$ ) and social norms ( $\mathrm{sig}$ $=0.015 ; \mathrm{r}=0.309$ ) had a positive and meaningful relationship with knowledge transfer in $95 \%$ confidence level and two other dimensions interrelationships and networks participation did not have a meaningful relationship with knowledge transfer. The dimensions of trust ( $\operatorname{sig}=0.017 ; \mathrm{r}=0.339)$ and networks participation ( $\mathrm{sig}=0.019 ; \mathrm{r}=0.295$ ) had a positive and meaningful relationship with knowledge creation. In addition, the dimensions of interrelationships and social norms did not have a meaningful relationship with knowledge creation. Three dimensions of trust ( $\operatorname{sig}=0.000 ; \mathrm{r}=0.501$ ) and social norms ( $\operatorname{sig}=0.017 ; \mathrm{r}=0.301)$ and networks participation $(\mathrm{sig}=0.047 ; \mathrm{r}=0.239)$ had a positive and meaningful relationship with knowledge record in $65 \%$ confidence level, but interrelationships did not have a meaningful relationship with knowledge record (Table 4).

\section{Table 4}

Pearson correlation coefficient of Sub-hypothesis

\begin{tabular}{|c|c|c|c|c|}
\hline Variables & Networks & Social norms & Trust & interrelationships \\
\hline Knowledge & 0.209 & $0.308^{*}$ & $0.314^{*}$ & 0.092 \\
\hline sig & 0.072 & 0.015 & 0.013 & 0.264 \\
\hline Knowledge & 0.182 & 0.222 & $0.376 * *$ & 0.178 \\
\hline Sig & 0.103 & 0.061 & 0.004 & 0.109 \\
\hline Knowledge transfer & 0.160 & $0.309^{*}$ & $0.316^{*}$ & -0.029 \\
\hline sig & 0.133 & 0.015 & 0.013 & 0.420 \\
\hline Knowledge creation & 0.295 & 0.221 & $0.339 * *$ & 0.207 \\
\hline sig & 0.019 & 0.062 & 0.008 & 0.074 \\
\hline Knowledge record & $0.239 *$ & $0.301 *$ & $0.501 * *$ & 0.062 \\
\hline sig & 0.047 & 0.017 & 0.000 & 0.334 \\
\hline
\end{tabular}

The structural model of the sub-hypothesis testing indicates that in studied population the direct effect of dimensions of interrelationships and network participation were not meaningful on none of the dimensions of knowledge management. In addition, the direct effect of dimension of trust on all 
dimensions of knowledge management except knowledge creation was meaningful and the direct effect of dimension of social norms on knowledge record, transfer and application was meaningful and was not meaningful with knowledge creation and acquisition. In other words, none of the dimensions of social capital effects on knowledge creation (See Table 5).

\section{Table 5}

Index model

\begin{tabular}{|c|c|c|c|c|c|}
\hline Route coefficient & Route coefficient & Sig. & $\mathrm{t}$ & $\mathrm{F}$ & $\mathrm{R}^{2}$ \\
\hline Knowledge application...Interrelationships & -0.023 & 0.887 & -0.142 & & \\
\hline Knowledge application....trust & $0.351^{*}$ & 0.029 & 2.256 & & \\
\hline Knowledge application....social norms & $0.273^{*}$ & 0.039 & 2.127 & & \\
\hline \multirow[t]{2}{*}{ Knowledge application.....networks participation } & -0.170 & 0.443 & -0.774 & & \\
\hline & & & & 2.594 & 0.187 \\
\hline Knowledge acquisition ...Interrelationships & 0.114 & 0.485 & 0.704 & & \\
\hline Knowledge acquisition....trust & $0.425^{*}$ & 0.009 & 2.745 & & \\
\hline Knowledge acquisition....social norms & 0.294 & 0.098 & 1.688 & & \\
\hline \multirow[t]{2}{*}{ Knowledge acquisition.....networks participation } & -0.260 & 0.238 & -1.195 & & \\
\hline & & & & 2.775 & 0.198 \\
\hline Knowledge transfer ....Interrelationships & -0.158 & 0.327 & -0.199 & & \\
\hline Knowledge transfer.....trust & $0.398^{*}$ & 0.012 & 2.628 & & \\
\hline Knowledge transfer ... social norms & 0.422 & 0.017 & 2.470 & & \\
\hline \multirow[t]{2}{*}{ Knowledge transfer ...networks participation } & -0.195 & 0.366 & -0.193 & & \\
\hline & & & & 3.349 & 0.229 \\
\hline Knowledge creation ... Interrelationships & 0.058 & 0.729 & 0.349 & & \\
\hline Knowledge creation....trust & 0.282 & 0.038 & 1.776 & & \\
\hline Knowledge creation ... social norms & 0.140 & 0.439 & 0.781 & & \\
\hline \multirow[t]{2}{*}{ Knowledge creation ...networks participation } & 0.045 & 0.841 & 0.202 & & \\
\hline & & & & 2.016 & 0.152 \\
\hline Knowledge record .... Interrelationships & -0.102 & 0.490 & 0.696 & & \\
\hline Knowledge record....trust & $0.577 * *$ & 0.000 & 4.139 & & \\
\hline Knowledge record ....social norms & 0.381 & 0.019 & 2.430 & & \\
\hline \multirow[t]{2}{*}{ Knowledge record ...networks participation } & -0.206 & 0.3 & -1.048 & & \\
\hline & & & & 6.014 & 0.348 \\
\hline
\end{tabular}

Table 6

Goodness of fit

\begin{tabular}{cccccc}
\hline RMSEA & sig & df & Chi-square & X2 & t \\
\hline 0.114 & 0.00549 & 43 & 70 & 1.62 & 1.49 \\
\hline
\end{tabular}

Regression formula of the dimensions of social capital with the dimensions of knowledge management is as follows:

Knowledge application $=0.373($ norm $)+0.351$ (trust) +0.901

Knowledge acquisition $=0.425$ (trust) +0.895

Knowledge transfer $=0.422($ norm $)+0.398$ (trust) +0.878

Knowledge record $=0.577$ (trust) $+0.381($ norm $)+0.790$

The result of the testing shows that according to the ratio of chi-square on degree of freedom is less than $2\left(\frac{x^{2}}{d f}=\frac{70}{43}=1.62\right)$ and the amount of RMSEA with the approximation error of square root of variance estimates is less than $0.5(\mathrm{RMSEA}=0.114)$, so it can be said that the above model will be a good fit of real world data. That is, in sum, the totality of structural equation, variables that determine social capital and knowledge management has been approved in the studied spatial domain (Table 6). 


\section{Discussion}

Findings of the research shows that the average of the dimensions of social capital in studied centers were at the intermediate level, but the average of the knowledge management were at the lower level of the intermediate. It seems that these centers have a relatively well social capital, but they are weak in association with knowledge management. In addition, the findings of the research show that there was a positive and meaningful relationship between social capital and knowledge management. Moreover, social capital in studied population had direct and meaningful effect on knowledge management in $95 \%$ confidence level. In other words, with the increase of the social capital in knowledge-based organizations, the process of knowledge management will be effectively implemented in organizations. It can be said that when an organization's level of social capital exceeds, brain management is manifested and leads to rapid growth of knowledge and technology will be more knowledge-based. This results are consistent with other researches findings (Tymon \& Stumpf, 2003; Das \& Teng, 2002; Mahmodi Topkanlo, 2011; Demori, 2009; Alvani et al., 2007; Zomorodiyan, 2010; Golmohamadnejad \& Mahdavi, 2011; Aebeli \& Zareh, 2013; Moghimi, 2008).

This research shows that none of the dimensions of social capital had direct effect on knowledge creation. The dimension of trust had the direct effect on all the components of social capital except knowledge creation. This fact shows that the trust facilitates the information exchange among sides and causes that individuals with trust to the opposite side, gives the information to the opposite side being sure that the opposite side does not misuse the information which cause to facilitate and accelerate knowledge sharing and application and information in the organization and among members. Moreover, the dimensions of social norms had direct and meaningful relationship with all the components of social capital except knowledge creation and acquisition. In fact, among the components of social capital, trust and social norms have a direct and meaningful relationship with the dimensions of knowledge management. In this regard, some of the researches report the same results (Demori, 2009).

The results show that other components of social capital did not have a direct and meaningful relationship with the components of knowledge management separately. It seems that there was a positive and meaningful relationship between social capital and knowledge management, but among all of the components of these indexes, there was not a direct and meaningful relationship with each other, which can have different reasons:

1. The possibility of indirect relationship among these components can be proposed, which can be the field of research of further researchers.

2. Being low the average of knowledge management in studied center can be considered, because of lack of attention of these centers to organizational knowledge management and non-optimal use of manpower and university elites and also the importance of these centers to quantity rather than quality.

In this research, attempts are accomplished to present a comprehensive framework to associate recent researches and the theories about the dimensions of knowledge management and social capital toward analyzing the role of the social capital on knowledge management. However, the organization should manage all its sets and social system, because access to organizational goals and obtaining the sustainable competitive advantage would be possible through the resultant of the activities of the dimensions of this capital.

The effect of social capital on developing organizational knowledge and organizational learning converts the organizations to knowledge-based organization and makes them close toward achieving the learner organization. The study showed that in studied population there was a correlation between social capital and knowledge management and knowledge-based organizations can promote the 
process of knowledge creation, acquisition, record, application and transfer by improving the social capital and through this increase their invisible properties.

\section{Conclusions}

Recommendation of the researchers of this article is to put more efforts for educational organizations in social capital section. In order to realize this fact, the organization requires identifying overt and covert human potentials within the organization, right social communications, creating social trust, employing and participating the specialists and professionals and elites, training for the deployment the human culture of collective participation and actual and potential resources which are toward progress of the organization.

\section{Acknowledgement}

The authors would like to thank the anonymous referees for constructive comments on earlier version of this paper.

\section{References}

Adler, P. S., \& Kwon, S. W. (2002). Social capital: Prospects for a new concept. Academy of management review, 27(1), 17-40.

Aebeli, K., \& Zareh, M. (2013).The relationship between social capital and organizational knowledge management in a public insurer. Insurance Journal, 28(2), 129152. [In Persian]

Alagheh band, M. (2005). The efficacy of social capital. Journal of Sociology of Knowledge, 42.[In Persian]

Alvani, M., \& Nategh, T., \& Farahi, M. (2007). The role of social capital in the development of knowledge management. Iranian Journal of Management Sciences, 2(5), 3570. [In Persian]

Bhatt, G. D. (2001). Knowledge management in organizations: examining the interaction between technologies, techniques, and people. Journal of knowledge management, 5(1), 68-75.

Coleman, J. S. (1998). Foundations of social theory. Harvard University Press.

Chalabi, M.(1996). Discipline of sociology: a theoretical explanation and analysis of the social order. Tehran: Ney Publication.

Das, T. K., \& Teng, B. S. (2002). Alliance constellations: A social exchange perspective. Academy of management review, 27(3), 445-456.

Demori, D. (2009). The role and relationship between social capital and knowledge management at Islamic University. Noor magazine, 41, 4464. [Persian]

de Jong, J. A., \& Roelofs, E. C. (2000). Knowledge management in the HRD office: a comparison of three cases. Journal of Workplace Learning, 12(7), 286-295.

Golmohamad nejad, G., \& Mahdavi, M. (2011).Investigate the relationship between social capital and knowledge management in high school girls in Tabriz. Educational Administration Research Quarterly, 2(4), 7190. [Persian]

Landry, R., Amara, N., \& Lamari, M. (2002). Does social capital determine innovation? To what extent?. Technological forecasting and social change,69(7), 681-701.

Mahmodi Topkanlo, H. (2011). The relationship between social capital and the extent of implementation of knowledge management. Thesis, Master of Library and Information Sciences School of Education and Psychology University of Mashhad. [In Persian]

Moghimi, M.(2008) .Organization and Management Approach. Tehran. Termeh Publication. [In Persian]

Skyrme, D. (1997). Knowledge management: making sense of an oxymoron. Management Insights, 22.

Tymon, W. G., \& Stumpf, S. A. (2003). Social capital in the success of knowledge workers. Career Development International, 8(1), 12-20. 
Winter, L. (2000).toward a theorized understanding of family life and social capital . Working Paper No.21, April 2000 Australian Institute of Family Studies.

Zomorodiyan, G. (2010). Establishment of knowledge management system based on social capital. Journal of Management Accounting, 3(5), 4563. [In Persian] 